\title{
Design of Launch Abort System Thrust Profile and Concept of Operations
}

\author{
Daniel Litton ${ }^{1}$ \\ NASA Langley Research Center, Hampton, VA, 23681 \\ Stephen A. O'Keefe ${ }^{2}$ \\ Analytical Mechanics Associates, Hampton, VA, 23666 \\ Richard G. Winski ${ }^{3}$ \\ National Institute of Aerospace, Hampton, VA, 23666 \\ John B. Davidson ${ }^{4}$ \\ NASA Langley Research Center, Hampton, VA, 23681
}

\begin{abstract}
This paper describes how the Abort Motor thrust profile has been tailored and how optimizing the Concept of Operations on the Launch Abort System (LAS) of the Orion Crew Exploration Vehicle (CEV) aides in getting the crew safely away from a failed Crew Launch Vehicle (CLV). Unlike the passive nature of the Apollo system, the Orion Launch Abort Vehicle will be actively controlled, giving the program a more robust abort system with a higher probability of crew survival for an abort at all points throughout the CLV trajectory. By optimizing the concept of operations and thrust profile the Orion program will be able to take full advantage of the active Orion LAS. Discussion will involve an overview of the development of the abort motor thrust profile and the current abort concept of operations as well as their effects on the performance of LAS aborts. Pad Abort (for performance) and Maximum Drag (for separation from the Launch Vehicle) are the two points that dictate the required thrust and shape of the thrust profile. The results in this paper show that $95 \%$ success of all performance requirements is not currently met for Pad Abort. Future improvements to the current parachute sequence and other potential changes will mitigate the current problems, and meet abort performance requirements.
\end{abstract}

\section{Introduction}

Aborts from the launch pad to early flight of the Crew Launch Vehicle (CLV) second stage are performed using the Launch Abort System (LAS). During a LAS abort, the LAS Abort Motor is used to pull the Crew Module (CM) safely away from the CLV and Service Module. The term Launch Abort Vehicle (LAV) will be used to refer to the LAS and CM together, prior to jettison of the LAS. The LAV consists of an abort motor to provide the thrust necessary for the LAV to separate from the CLV, an Attitude Control Motor (ACM) to provide attitude and rate control, and a jettison motor to separate the LAS from the CM. LAS aborts remain a viable option until the LAS is jettisoned during the second stage of CLV flight1.

There are many key elements to ensuring that the LAS will successfully bring the crew back to Earth in the event of a launch vehicle failure. When the shape of the LAV was changed to a new lower drag configuration, this study was commissioned to see what potential weight benefits could be achieved by changing the Abort Motor Thrust profile. However, it was soon discovered that the $95 \%$ success rate of abort criteria was not being met for the nominal thrust profile, nor could it be met by changing the Abort Motor thrust profile alone. At this point a careful look into the abort sequence concept of operations began.

\footnotetext{
${ }^{1}$ Aerospace Engineer, Member

${ }^{2}$ Project Engineer

${ }^{3}$ Research Engineer, Member

${ }^{4}$ Aerospace Engineer, Senior Member
} 
The designs of the LAS Abort Motor and Concept of Operations both take advantage of the LAS's active control system. Where the Apollo program had an open-loop timer-based system utilizing a set of passive canards to reorient the LAS to a heatshield forward orientation during the abort sequence, the Orion LAV makes use of a closed loop system with an Attitude Control Motor (ACM) to actively ensure stability and reorient the vehicle to heatshield forward flight. The addition of the ACM to the Launch Abort Vehicle (LAV) provides an upgrade over the Apollo system capabilities, enabling a controlled pitch maneuver away from the Launch Vehicle and towards water (from $\mathrm{pad} / \mathrm{near}$ pad abort), and also control through all regimes of flight. One of the largest benefits of the ACM is to give the LAS control robustness for all regimes of flight and a much smaller landing and mass footprint. The mass reduction comes from removing the 1000 pounds of ballast that the Apollo system required to maintain stability during the pitch and coast stages of the abort sequence.

The first major design parameter is the Abort Motor thrust profile. It must be able to pull the LAV away from a failed launch vehicle at all abort conditions along the CLV trajectory while also providing enough performance to meet all the requirements at Pad Abort. All profiles considered during this study were constrained to the same total impulse to prevent outer-mold-line change and weight gains, but altered the timing of when that impulse was applied in order to balance the demands of all abort conditions.

The second major design parameter is the Concept of Operations. The typical abort Concept of Operations starts with a pitch maneuver during the Abort Motor burn to orient the LAV either out to water or away from a failed launch vehicle, followed by a brief coast period, a reorientation to heatshield forward flight, Launch Abort Tower Jettison (Tower Jettison), and finally the parachute deployment sequence. The order and timing of these events as well as the shape of the pitch maneuver define the Concept of Operations. Figure 1 depicts the sequence of events for a general abort. Two key aspects of the Concept of Operations are the initial pitch maneuver and the time of LAS jettison. Both of these aspects have a great impact on the achieved altitude and downrange distance of the vehicle. The development of an optimized sequence is a complicated process that entails taking all aspects of the concept of operations into account and balancing them until the best possible solution is found.

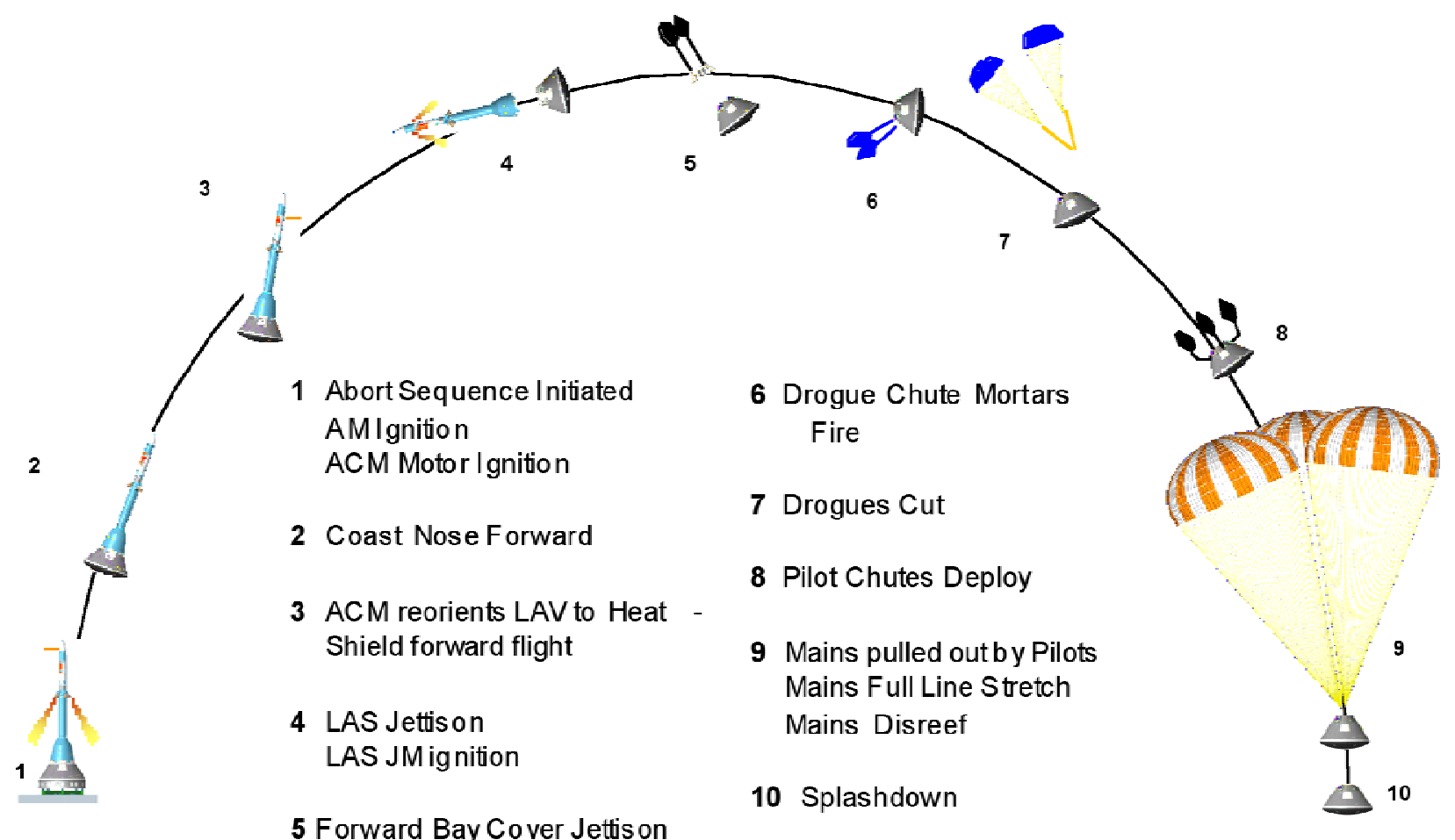

Figure 1. General abort sequence of events.

iSight and the Program to Optimize Simulated Trajectories II (POST2) ${ }^{2}$ are used to optimize the Abort Motor thrust profile and the Concept of Operations. Close attention is paid to both the Pad Abort and an abort at the maximum drag (of the LAV) along the CLV trajectory (Max Drag), two of the limiting cases for LAS success. These two cases are of interest because of the higher degree of difficulty in achieving all success criteria and due to the fact that they are the bounding cases for stability, performance, and separation distance from the launch vehicle. 


\section{Model Description}

POST2, a Six Degree of Freedom (6 DoF) model has been used to develop the launch abort simulation and perform Monte Carlo analyses. POST2's development began in the 1970's, as POST, and has been used for a wide variety of atmospheric ascent and descent problems and exo-atmospheric orbital transfer problems. Flight projects including the Space Shuttle, Mars Science Laboratory, Phoenix, Mars Pathfinder, Hyper-X, Stardust, Genesis, and many other have all benefited from its unique capabilities. Within POST2 the 1999 Global Reference Atmospheric $\mathrm{Model}^{3}$ is used to model atmospheric effects and variations. The controller used for the LAS active control system is a hybrid design, including features developed by the government and the primary contractor. The controller uses a proportional, integral, and derivative (PID) approach to control the ACM. In addition to maintaining vehicle stability, the controller also enables changes to the Concept of Operations such as the initial pitch maneuver and the event sequencing.

For Monte Carlo analysis at Pad Abort, 1840 different wind profiles taken over the past 40 years at Kennedy Space Center (KSC) are used to model wind conditions. The wind profiles are divided equally between each of the twelve months of the year. The KSC wind set only encompasses altitudes up to 10,000 feet, therefore, for the Max Drag case the GRAM993 model is used to produce the necessary wind profiles in addition to the atmospheric properties. All aerodynamics are taken from the "Orion Aerodynamic Databook4," provided by the CEV Aerosciences Project team. A rotating, oblate Earth gravity model with J2-J4 gravity terms is used in POST2.

iSight is a wrapper used to perform optimizations in addition to POST2. In this study, iSight enables both the Pad Abort and Max Drag cases to be optimized at the same time. This methodology ensures that new abort motor profiles meet the separation requirements at max drag as well as performance metrics at Pad Abort.

The parachute model is a simple drag model applied to a 6 DoF vehicle (Command Module in this study). It has been compared against the Decelerates System Simulation (DSS) simulation, which uses a multibody parachute model, currently in use at NASA Johnson Space Center, with excellent results. The physical system consists of two drogue conical ribbon parachutes, three pilot ringslots parachutes and three main ringsail parachutes ${ }^{0}$. However, for the POST2 simulation one parachute is modeled in place of the cluster of main parachutes and cluster effects are neglected. The parachute inflations are modeled using empirically based fill time equations ${ }^{6 / 7}$. The nominal time line for pad abort is shown in Table 1. All the desired parachute dispersions may be applied using this simple parachute model. Dispersions on drag coefficient, parachute area, parachute fill times, and cutter times are applied in Monte Carlo analyses. Table 2 gives the current specifications for the parachute designs. Note that the reefing time on the drogue parachutes is longer than the nominal timeline, and that the drogue parachutes are never fully opened. Note also that the values given here are intermediate and are continually updated depending on further simulation and test data.

The philosophy behind this parachute model is to use a sufficiently complex model to capture key dynamics by simply specifying an attachment location of the capsule-parachute system while maintaining enough simplicity to facilitate its use for quick Monte Carlo analyses. The dynamics resulting from this model are conservative when compared to DSS, but sufficiently similar to results from a multibody model such that only worrisome cas-

Table 1. General Pad Abort Timeline

\begin{tabular}{lc}
\hline \multicolumn{1}{c}{ Event Description } & Time (sec) \\
\hline LAS Ignition & 0 \\
Thrust Tailofff & 2 \\
Thrust Off & 5 \\
Reorientation Start & 11 \\
Apogee & 18 \\
LAS Jettison & 21 \\
Forward Aeroshell Jettison & 21.5 \\
Drogue Mortar & 24.5 \\
Drogue Line Stretch & 25.5 \\
Drogue Cut Away & 31.5 \\
Main Pilot Deployment & 31.5 \\
Main Line Stretch & 35 \\
Main $1^{\text {st }}$ Disreef & 13 \\
Main Disreef to Full Open & 51 \\
Touchdown & 96 \\
\hline
\end{tabular}

Table 2. Current Parachute Properties

\begin{tabular}{|c|c|c|c|}
\hline Parameter & Drogue Parachute & Pilot Parachute & Main Parachute \\
\hline Cd (1 Parachute) & 0.55 & 0.52 & 0.7156 \\
\hline Cd (2 Parachutes) & 0.52 & - & 0.6918 \\
\hline Cd (3 Parachutes) & - & - & 0.8379 \\
\hline Diameter & $23.00 \mathrm{ft}$ & $9.36 \mathrm{ft}$ & $118.00 \mathrm{ft}$ \\
\hline $1^{\text {st }}$ Stage Reefing Ratio & $45 \%$ & - & $6.50 \%$ \\
\hline $1^{\text {st }}$ Stage Reefing Time & $14 \mathrm{~s}$ & - & $8 \mathrm{~s}$ \\
\hline $2^{\text {nd }}$ Stage Reefing Ratio & - & - & $12.70 \%$ \\
\hline $2^{\text {nd }}$ Stage Reefing Time & - & - & $16 \mathrm{~s}$ \\
\hline
\end{tabular}


es, such as the Command Module (CM) flipping while on parachutes, need be simulated using a multibody parachute model. POST2 will be transitioning to a model similar to DSS in the future.

\section{Success Constraints}

There are many constraints enforced to ensure that the crew lands safely. The first of which is that the LAV must reach a separation distance of 175 feet from the CLV at 3 seconds after abort initiation, and maintain this as a minimum throughout the remainder of the abort sequence. Also, the LAV must sustain forward flight until reorientation is commanded by the controller. During this time and until LAS jettison, total angle of attack times dynamic pressure must be no greater than $17,000 \mathrm{lb}-\mathrm{deg} / \mathrm{ft}^{2}$.

At drogue parachute deployment the following conditions must be met:

$$
\begin{gathered}
130^{\circ} \leq \alpha \leq 230^{\circ} \\
|\beta| \leq 50^{\circ} \\
\overline{\mathrm{q}} \leq 160 \mathrm{psf}
\end{gathered}
$$

At main parachute line stretch and beyond, the following conditions must be met:

$$
\begin{gathered}
110^{\circ} \leq \alpha \leq 250^{\circ} \\
|\beta| \leq 70^{\circ}
\end{gathered}
$$

When the system reaches $30 \mathrm{ft} / \mathrm{s}$, the $\mathrm{CM}$ must have an altitude greater than 540 feet. This requirement has been derived to cover for one main parachute out and one standard deviation on parachute dispersions. For Pad Abort the LAV must land in water with a depth of 10 feet or more. The 10 foot water depth line is located approximately 3100 feet from Pads 39 A and B at Kennedy Space Center (KSC) at an azimuth of 53 degrees.

Although a case may fail more than one requirement, each case that fails multiple criteria only counts once towards the total number of failures. When all successful cases are totaled, they must exceed $95 \%$ of the total number of Monte Carlo runs.

\section{Methodology}

iSight and POST2 are used to implement an optimization of the Abort Motor thrust profile and the Concept of Operations. In order to do this, both the Pad Abort and Max Drag cases are solved simultaneously to ensure that all success requirements are met. These two cases are chosen due to the degree of difficulty in meeting performance metrics and are the bounding cases for the LAV's stability, performance, and separation distance from the launch vehicle. These two cases are optimized nominally and then tested in a Monte Carlo to ensure that the requirements are met for all dispersed conditions. The Pad Abort Monte Carlo set included 1840 cases that varied many vehicle properties including aerodynamics, mass properties, Abort Motor engine nozzle orientations, bulk temperature of the Abort Motor propellant, and wind conditions.

Both the thrust profile and concept of operations were optimized. The thrust profile is optimized by specifying a two tier thrust profile, a higher thrust setting initially followed by a lower thrust setting. Typically, the higher thrust allows the vehicle to separate quickly at Max Drag, while the lower setting spread over a longer time allows the vehicle to better reach Pad Abort altitude and downrange requirements. Figure 2 shows the effect of extending the thrust over a longer duration. With the extended thrust, the vehicle is now thrusting while the flight path angle is lower, enabling the vehicle to obtain more downrange, and better over all performance. Another potential addition to the Abort motor is slivers. Slivers are inert substances used to alter the burn rate of the propellant. By placing slivers in the Abort Motor it is possible to extend the nominal thrust setting for a longer period of time, reduce the tail-off, and enhance the performance of the LAV, while maintaining the same impulse. Four different profiles were examined: the original baseline profile, called the Wagon Wheel Profile, the optimized profile, and two feasible/realistic versions of the optimized profile with a long and a short tail-off.

The Concept of Operations is optimized by changing the initial pitch maneuver, LAV reorientation time and the time for jettison of the LAS. The optimization of the nominal Abort Motor thrust profile and Concept of Operations is a highly non-linear problem. First, iSight and POST2 are run to generate a nominal optimized solution. This initial 
solution is then tested in a Monte Carlo run, the results of which are then used to modify the constraints of the nominal case. The constraints used in the optimization process differ from the listed constraints in order to account for offnominal cases, aiding in ensuring that the Monte Carlo will meet the 95\% success criteria. This optimization process is iterated until both the nominal and the Monte Carlo results pass all success criteria. Due to the iterative nature of this process, the criteria for the nominal solution become ranges as opposed to absolute values. In order for a dispersed Pad Abort to be successful, the non-dispersed Pad Abort should meet the following criteria: the altitude at LAS jettison must be greater than approximately 5300 feet; the altitude during descent when a velocity of 30 $\mathrm{ft} / \mathrm{s}$ is reached must be greater than approximately 1400 feet; the initial pitch maneuver must not exceed

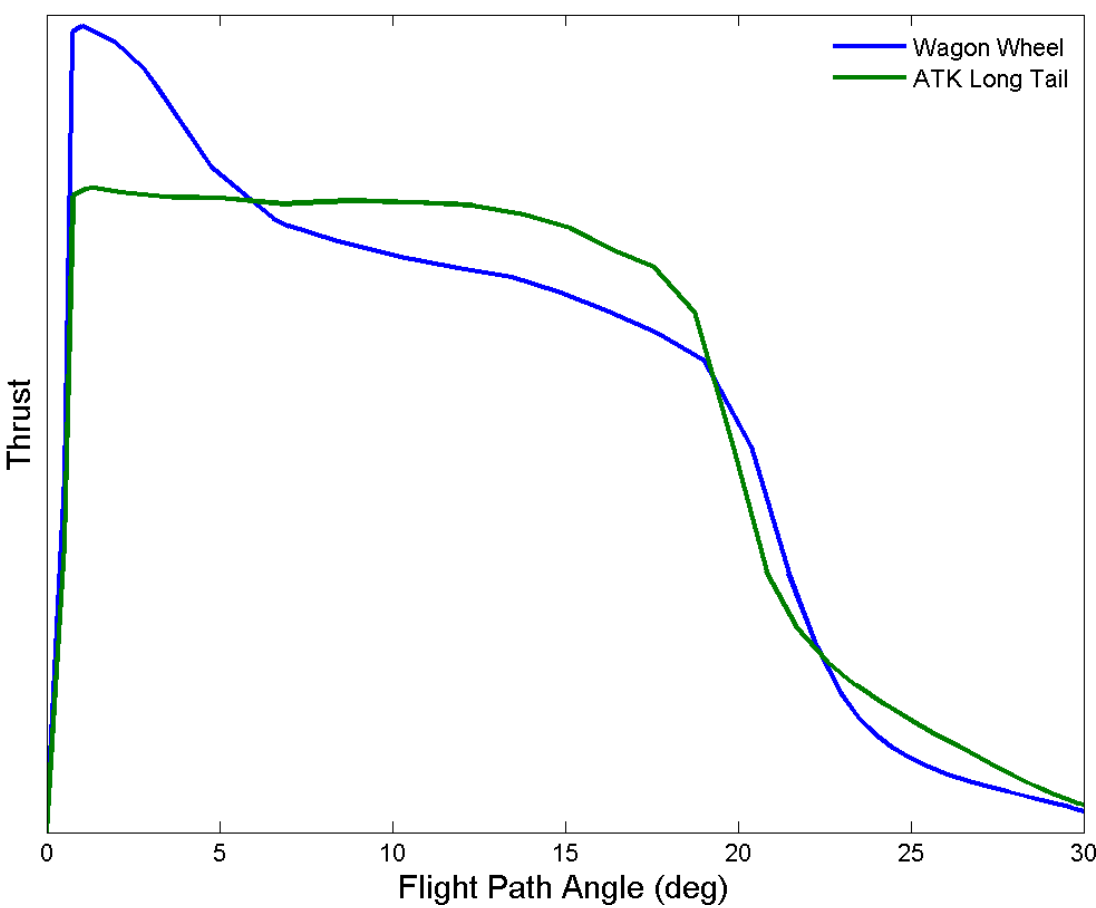

Figure 2. Thrust vs Flight Path Angle for Wagon Wheel and ATK Long Tail Profiles.

approximately 15 degrees angle of attack. The last criterion is determined through Monte Carlo analysis to be the breakpoint beyond which, when dispersed, the vehicle loses stability during the pitch maneuver. For Max Drag, the major constraint is the separation distance between the LAV and the CLV at 3 seconds after abort initiation must be greater than approximately 220 feet.

The main drivers in the optimization are the shaping of the pitch maneuver, maintaining forward flight before reorientation to heatshield forward (coast phase), settling time after reorientation, and the tower jettison time. Due to the decreased drag when the LAS is oriented nose forward, the longer the LAV remains in forward flight, the greater the achieved downrange distance. In contrast, reorienting too early can cause the ACM to lose control authority due to the high dynamic pressure. This lack of control authority can cause the LAV to overshoot the heatshield forward trim point and require additional settling time. Settling time is the time over which the vehicle attempts to stabilize itself by using the ACM after reorienting from LAS forward to heatshield forward flight, before jettisoning the LAS. Once the LAS jettisons, there is not enough time to turn on the CM RCS, therefore leaving the CM solely to it's own aerodynamic stability in order to remain in a stable flight conditions. Therefore, it is vital to jettison the LAS at the best possible dynamic conditions to ensure that the $\mathrm{CM}$ will not tumble or flip to apex forward in the time before drogue deploy. In addition, although there are currently no attitude/rate requirements at LAS jettison, the dynamics at this event feed forward into the dynamics at drogue deploy, on which there are constraints.

One problem with the current baseline Concept of Operations is the inability to meet $95 \%$ of all success criteria, especially when accounting for a failure of one main parachute. This "one main parachute out" constraint increases the altitude that the CM must be at when deploying the main parachutes. If in order to achieve this higher altitude later in the abort trajectory the initial pitch maneuver is less aggressive, the downrange distance will suffer. Essentially it is a trade between deploying the parachutes soon enough to slow the vehicle down to less than $30 \mathrm{ft} / \mathrm{s}$ and meeting the $10 \mathrm{ft}$ water depth line requirement. One method to gain back altitude without conceding as much downrange distance is to shallow out the trajectory and jettison the LAS closer to apogee. The original Concept of Operations jettisoned the LAS at 21 seconds into abort, approximately 3-4 seconds after trajectory apogee. The velocity in this region is on the order of 100-200 ft/s, resulting in an altitude loss of approximately 400-800 feet, as compared to a jettison at apogee.

Only a few optimization parameters were turned for the Max Drag case. The main change in this region is a switch to an azimuth bias during the pitch maneuver. Whereas the previous pitch maneuver stayed in the same plane of the CLV, the azimuth bias goes out of the plane of the CLV, essentially giving the trajectory some initial beta. 
The azimuth bias maneuver allows a less aggressive pitch maneuver, which aides in stability in this volatile region. Implementing this maneuver decreases the number of failures violating the minimum separation distance between the LAV and the CLV at times greater than three seconds into abort, but also increases the number of cases where control authority is lost during the initial pitch maneuver. By altering both the magnitude of the azimuth bias and the initial pitch maneuver it is possible to reduce the total number of failures lower than those incurred without an azimuth bias maneuver.

\section{Results}

To assess the impact of changing the Abort Motor thrust profile and the Concept of Operations numerous Monte Carlo cases have been run. The most important results are discussed below.

Max Drag is the case that drives the peak levels of thrust required to get away from a failed CLV and meet the $175 \mathrm{ft}$ in 3 seconds and greater metric. Through this study it has been determined that pad abort is fairly insensitive to reducing the peak level of thrust. Initially, the optimized thrust profile was determined from Monte Carlo results where the LAV had to deliver the crew safely $95 \%$ of the time at all conditions, including the $175 \mathrm{ft}$ separation at 3 seconds and beyond. This requirement changed soon after receipt of a realistic thrust profile (based upon optimized profile) from the Abort Motor Vendor, Alliant Techsystems (ATK). In order to save as much weight as possible, it was decided to change the thrust level so that $175 \mathrm{ft}$ of separation between the LAV and CLV was just met at three seconds. In addition, this requirement on the profile stood only for the nominal case (no dispersions on aerodynamics or mass properties) with the worst performing engine possible (cold temperature $\left(30^{\circ} \mathrm{F}\right)$ and -3 sigma engine profile). This change in requirement resulted in a profile with the same impulse, but with a $7 \%$ decreased peak magnitude as compared to the initial profile that was received from ATK. Figure 3 shows the initial optimized profile, the initial ATK profile, and finally the Wagon Wheel Profile. No results will be shown for the initial ATK Long Tail profile, but rather only for the ATK

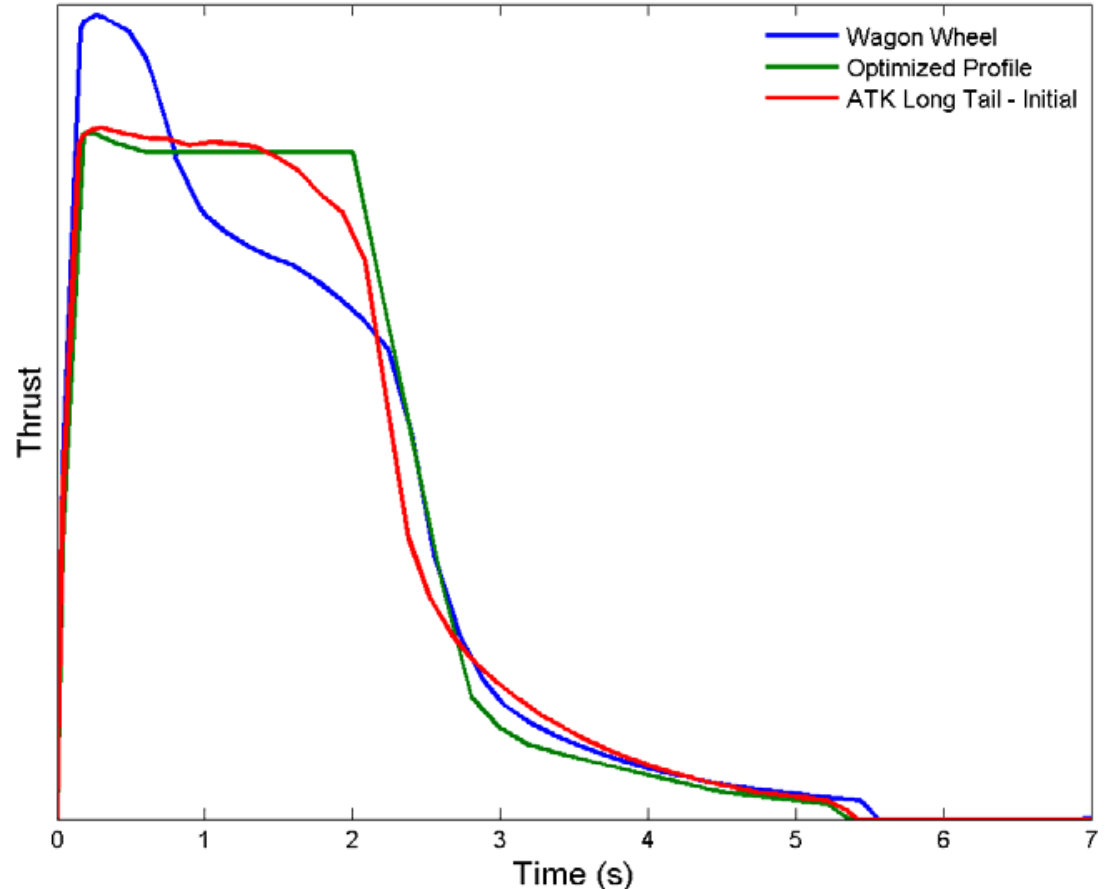

Figure 3. Comparison of wagon wheel to the Optimized and ATK's initial thrust profiles.

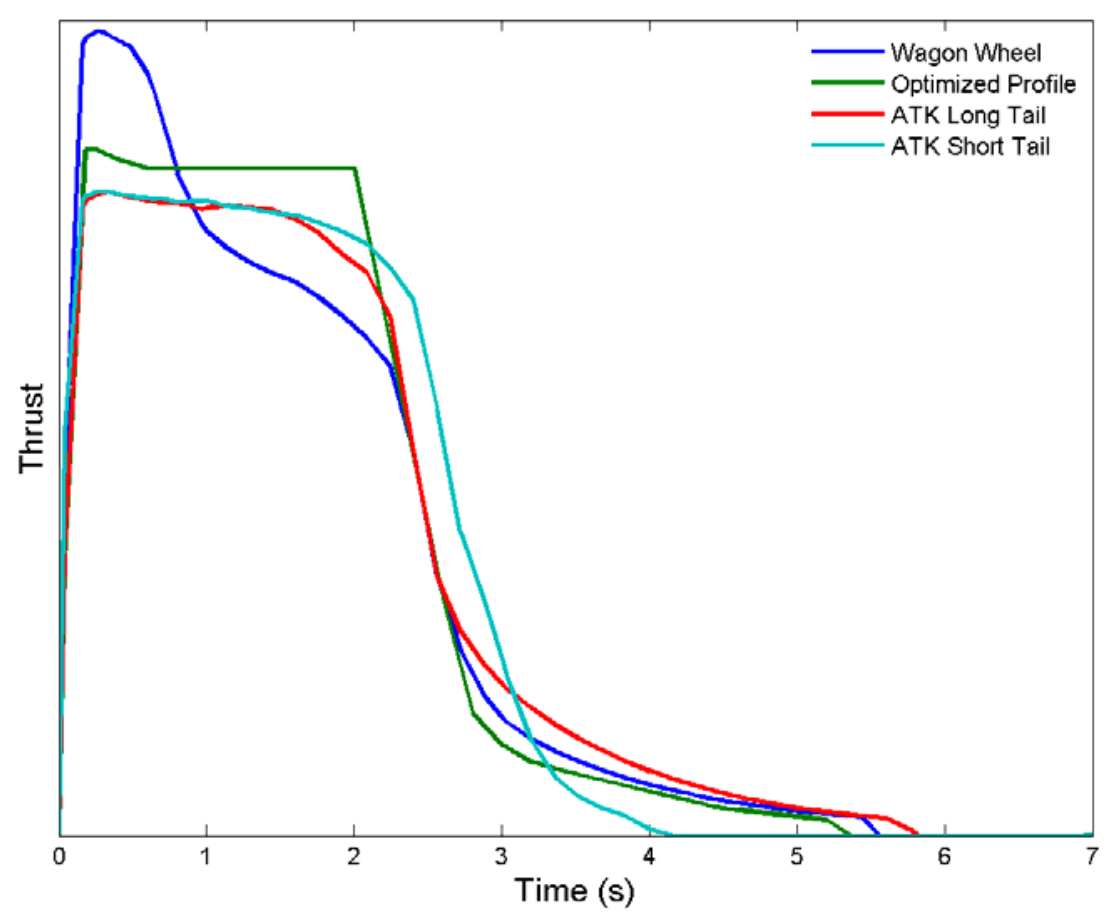

Figure 4. Comparison of Wagon Wheel to Optimized, ATK's Long and Short Tail reduced thrust profiles. 
Long Tail profile with the reduced thrust, shown in Figure 4. Finally, Figure 5 shows the impact on separation distance at Max Drag when going from the Wagon Wheel profile down to the reduced ATK Long Tail profile. Due to the higher initial thrust, the Wagon Wheel pulls away much quicker from the LAV in the initial 2 seconds than the ATK Long Tail profile. However, the ATK Long Tail profile catches up and passes the Wagon Wheel profile due to the longer duration of high thrust.

Figure 4 depicts the thrust profiles for the current baseline system, designated the Wagon Wheel profile, the optimized thrust profile with extended tailoff, and ATK's extended and a shortened tail-off. As a rule of this study, all four thrust profiles have the same impulse. From this figure, it is apparent that the

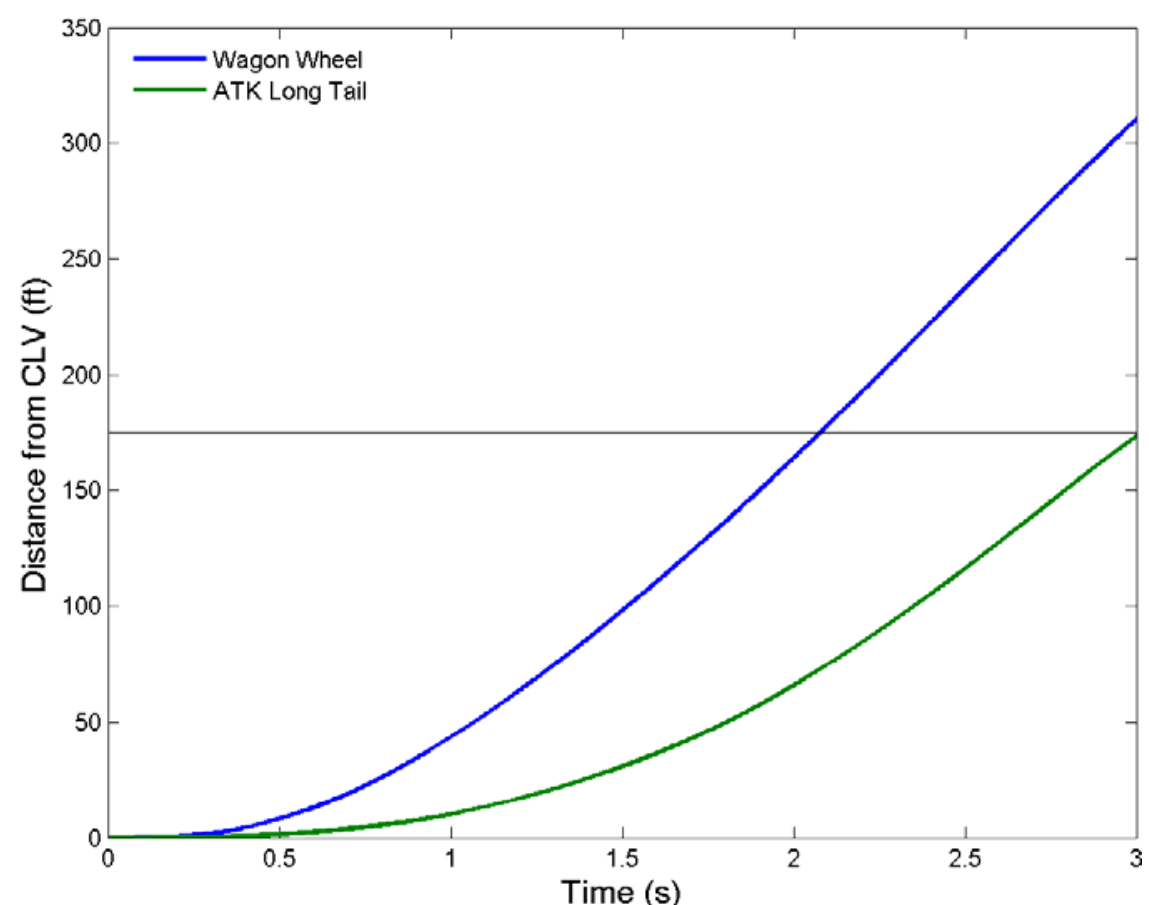

Figure 5. Separation Distance versus time at Max Drag for Wagon Wheel and ATK Long Tail profiles.

short tail-off enables a longer duration of usable thrust. It can also be seen that by reducing the initial impulse of the Wagon Wheel to that of the optimized profile, a lower level of thrust can be maintained for a longer period of time.

Pad Abort provides a difficult environment to be successful. One of the main factors in a successful Pad Abort is delivering the capsule to at least $10 \mathrm{ft}$ of water. The LAV is initially pointing vertically on the pad. In order to make effective use of the 2-3 seconds of usable thrust from the Abort Motor, the ACM has to point the vehicle towards the coast as quickly as possible. Most of the usable thrust for the Wagon Wheel is in the first 1-1.5 seconds. By spreading this thrust out over time, the LAV can take advantage of the fact that the flight path angle is closer to horizontal when there is still usable thrust. This point is demonstrated in Figure 2, which shows flight path angle versus thrust. It is readily apparent that the longer thrust profile enables the LAV to be thrusting at the lower flight path angles.

The importance of the thrust tail-off and thrusting for a longer duration at a lower level can be seen in Table 3, which shows the percent of failures of the optimized Monte Carlo runs for each of the four thrust profiles. The shortened tail-off produces approximately $3 \%$ fewer failures than the longer tail-off. While the tail-off plays a large role, altering the shape of the thrust profile gives the greatest advantage over the Wagon Wheel, a 5\% decrease in failures. Due to manufacturing issues and higher development risk, the team was directed to carry forward the extended tail-off thrust profile.

Table 3. Pad Abort results for optimized, ATK, and Wagon Wheel thrust profiles

\begin{tabular}{lccccc}
\hline \multicolumn{1}{c}{ Thrust Profile } & \multirow{2}{*}{ Wagon Wheel } & \multirow{2}{*}{ Optimized } & $\begin{array}{c}\text { ATK Long } \\
\text { Tail }\end{array}$ & $\begin{array}{c}\text { ATK Long Tail } \\
\text { Extra 1.5 s }\end{array}$ & $\begin{array}{c}\text { ATK Short } \\
\text { Tail }\end{array}$ \\
\hline Tower Jettison Time (s) & 18 & 18 & 18.0 & 19.5 & 18 \\
Failed 10 ft Water Line & 155 & 102 & 121 & 206 & 84 \\
Failed 540 ft at 30 ft/s & 64 & 39 & 46 & 118 & 27 \\
Failed Other Criteria & 9 & 5 & 8 & 2 & 5 \\
Total Failures & 228 & 146 & 175 & 326 & 116 \\
Percentage of 1841 Runs & $12.4 \%$ & $7.9 \%$ & $9.5 \%$ & $17.7 \%$ & $6.3 \%$ \\
\hline \hline
\end{tabular}




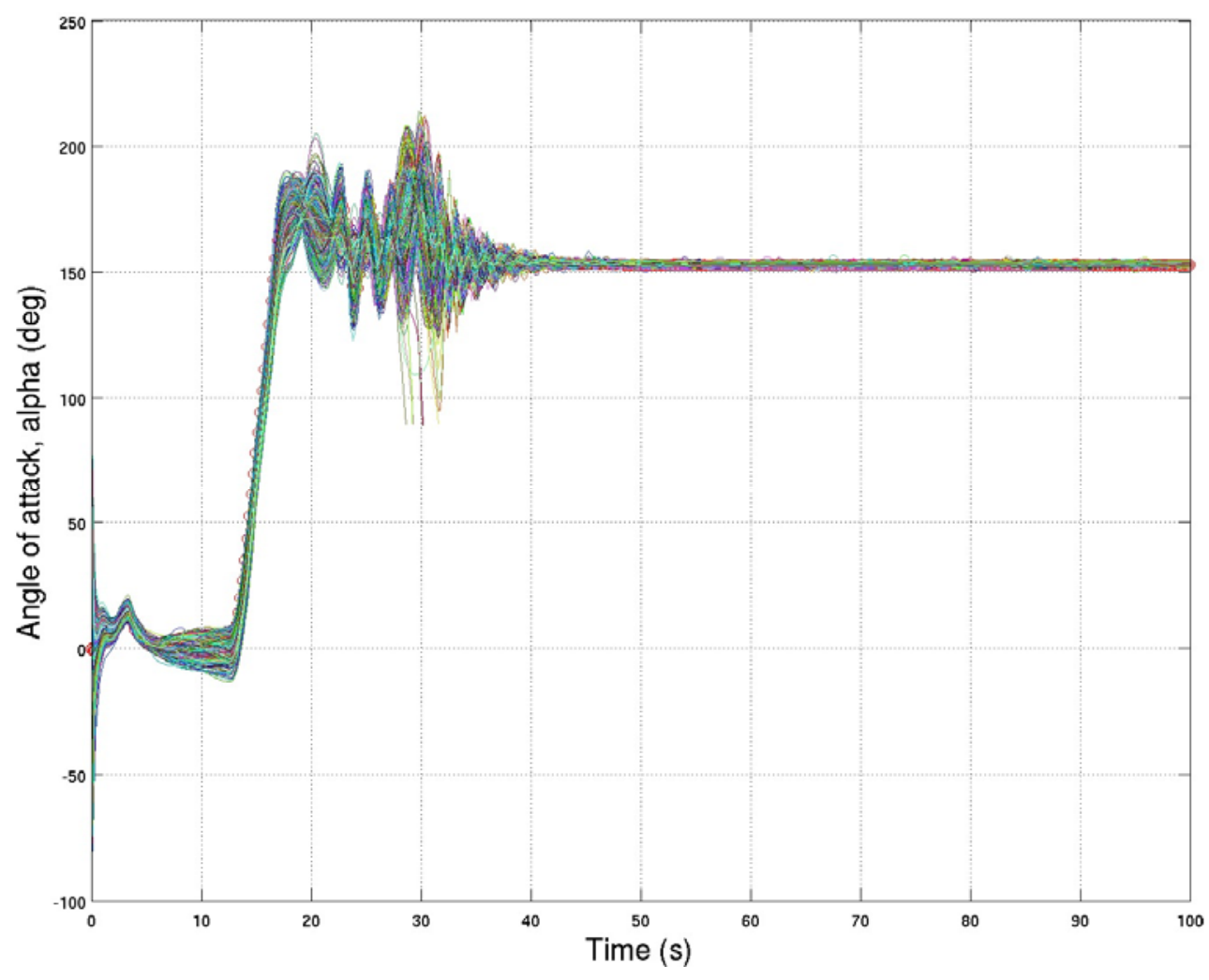

Figure 6. Time versus angle of attack for nominal settling time.

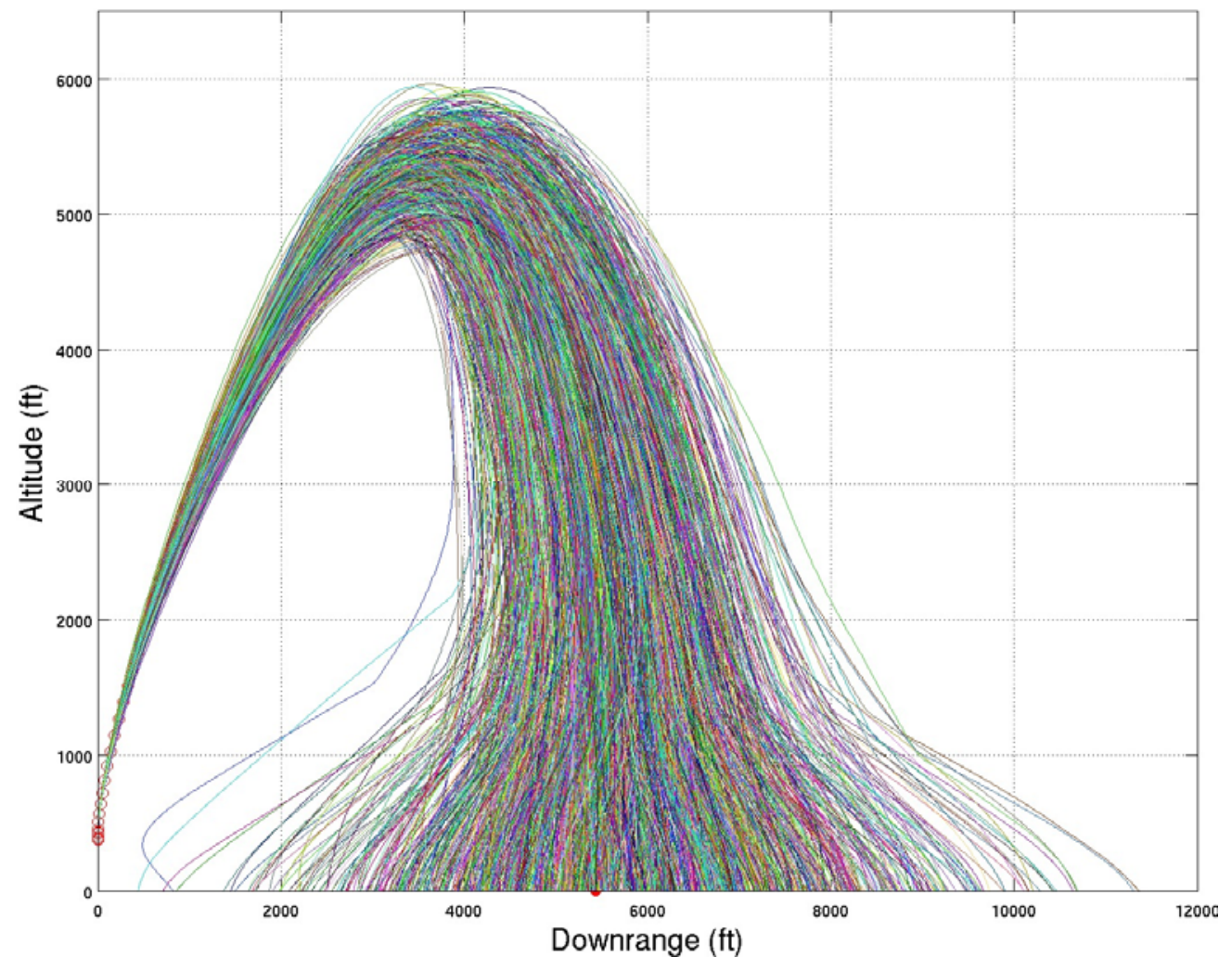

Figure 7. Altitude versus downrange for nominal settling time. 


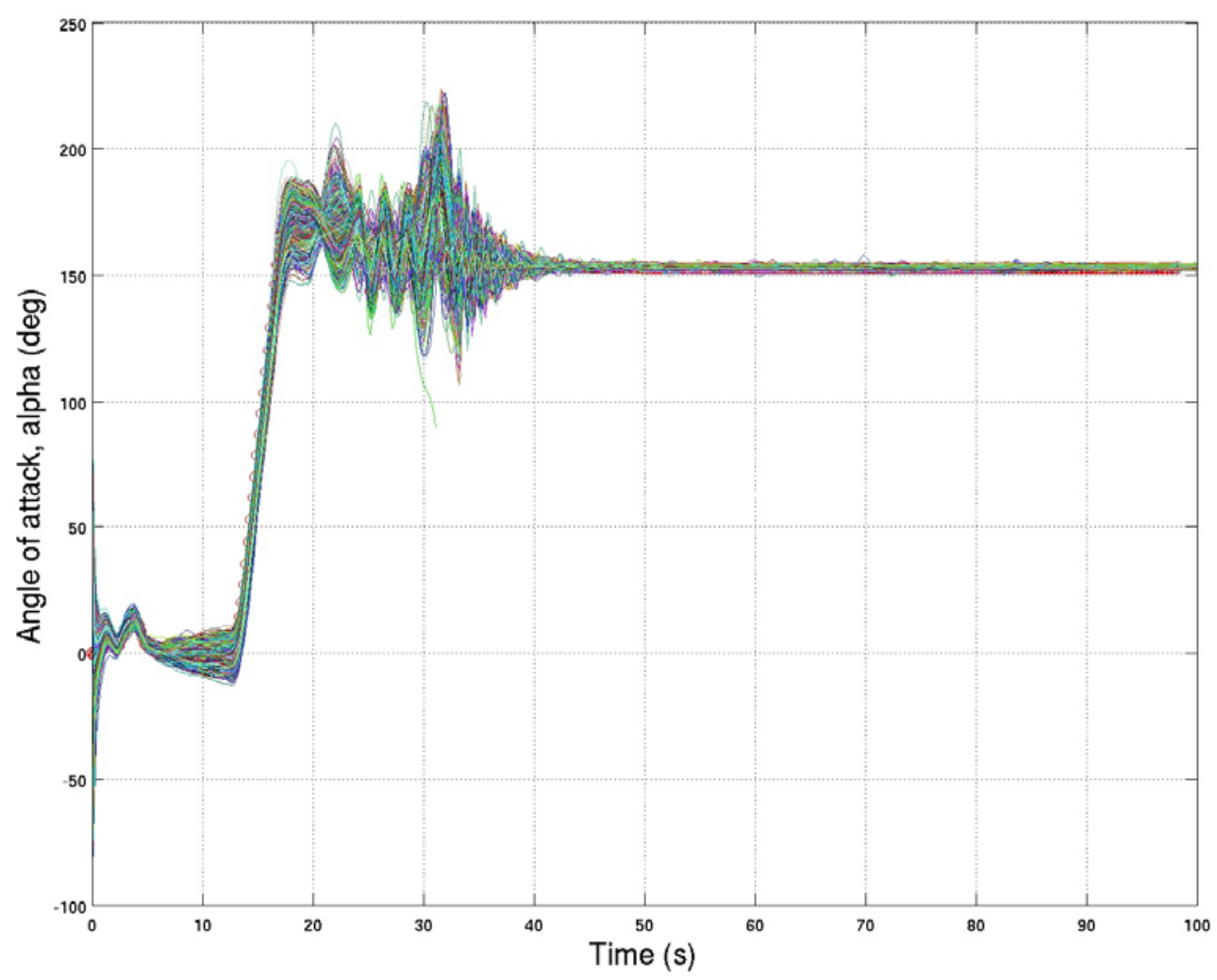

Figure 8. Time versus altitude for extra 1.5 seconds settling time.

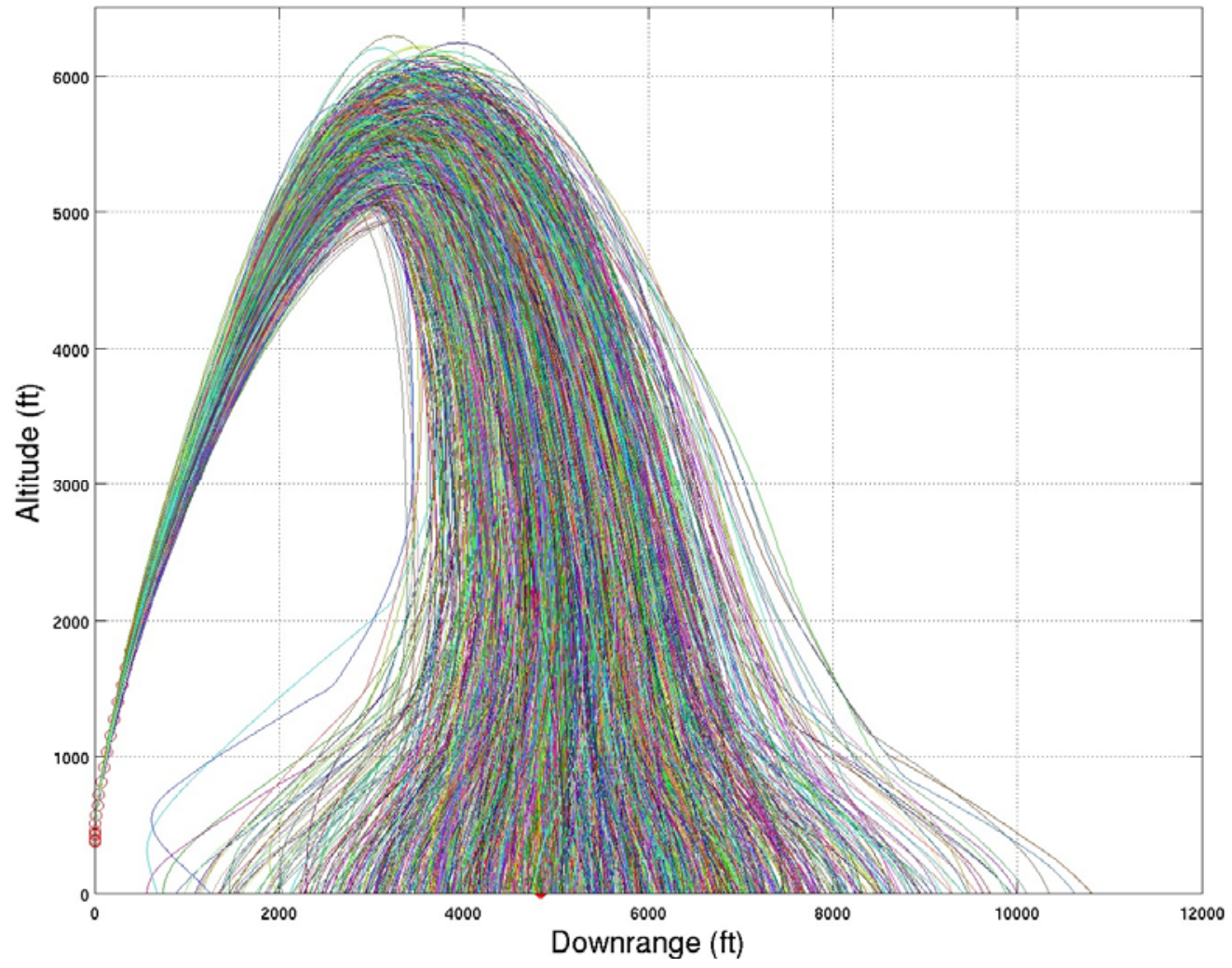

Figure 9. Altitude versus downrange for extra 1.5 seconds settling time. 
As mentioned previously, the amount of settling time is a very important factor in a successful pad abort. Figures 6 through 9 show the effects of adding an extra 1.5 seconds of settling time after reorientation. For this example, all of the other parameters are exactly the same between the two cases, including the use of the ATK Long Tail thrust profile. Both cases are fully optimized from the beginning of the trajectory through tower jettison. The beginning of reorientation is set at 12.5 seconds for both cases. This is the earliest time the LAV can be reoriented without having high dynamic pressure aerodynamics due to the high dynamic pressure overpower the ACM, causing overshoot after reorientation and higher than allowable dynamics at drogue deploy. To account for

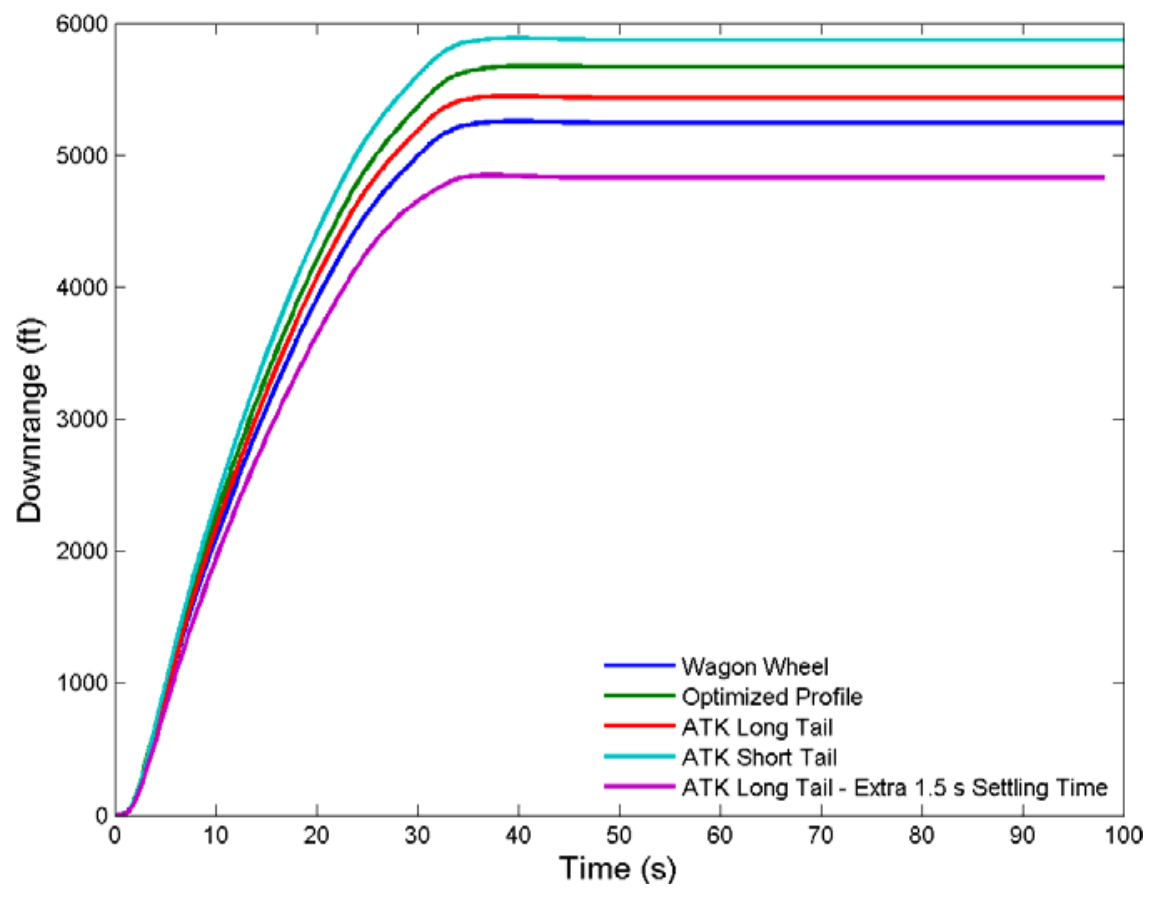

Figure 10. Downrange versus time for nominal, non-dispersed runs. the extra 1.5 seconds of settling time, tower jettison has been moved from 18 seconds to 19.5 seconds.

For Pad Abort, the major trade is between ensuring the $\mathrm{CM}$ is at $30 \mathrm{ft} / \mathrm{s}$ by the time it reaches $540 \mathrm{ft}$ and ensuring landing in $10 \mathrm{ft}$ depth of water or greater. The optimization process determines the best pitch profile that meets all objectives, while minimizing the total number of failures. In doing so, the major drivers are balanced as equally as possible to minimize the total number of failures. The final results show that the addition of 1.5 seconds of settling time has increased the total number of failures from 175 to 326 , an increase of $8 \%$. This change can be explained by comparing the downrange and altitude ranges for each Monte Carlo in Figures 7 and 9. Figure 9 shows a more lofted trajectory when compared to Figure 7, which causes a loss in downrange, on the order of $600 \mathrm{ft}$, as can be seen in Figure 10. In comparing the means of the two cases it can be seen that the extra 1.5 seconds of settling time has caused the maximum altitude mean to rise by $249 \mathrm{ft}$, from 5313 to $5562 \mathrm{ft}$. This upward shift in the mean altitude is the reason the
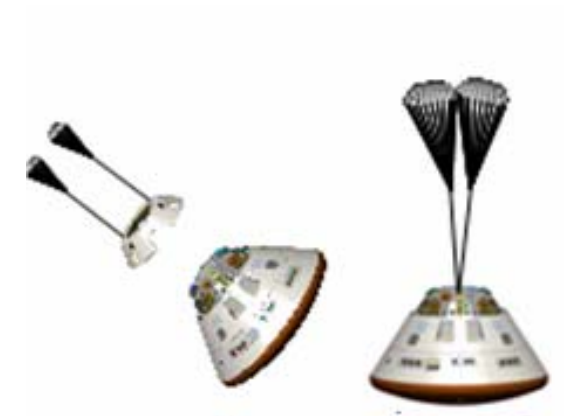

FBC Jettison Drogue Deploy
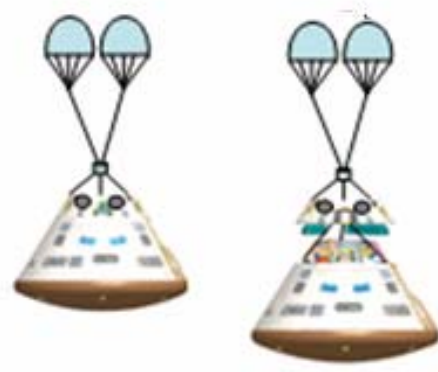

Drogue Deploy

Drogue Cut FBC Jettison
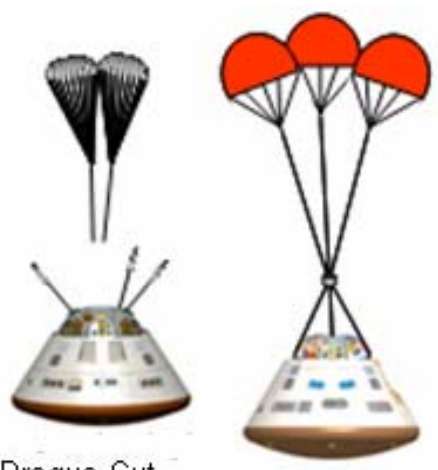

Drogue Cut Pilot Mortar

Main Fully Inflated
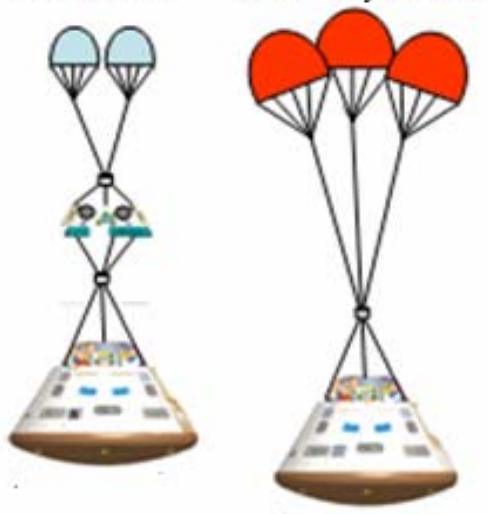

Main Deploy

Main Fully Inflated

Figure 11. Old Baseline Chute Sequence (Top) and New Baseline Chute Sequence (Bottom). 
LAV's performance decreases. On the other hand, from Figures 6 and 8, it can readily be seen that the extra 1.5 seconds of settling time does have the intended effect of damping the dynamics at tower jettison (19.5 seconds) and beyond. For example, there are not as many cases that flip between drogue parachute line cut and main parachute line stretch. Table 1 shows all these results numerically in addition to the comparison in performance between the profiles. This comparison demonstrates the importance and sensitivity when considering the amount of settling time needed for the LAV system.

Although the system does not close at this time, there are major changes in the chute sequence that will push pad abort across the threshold. Figure 11 details how the chute concept of operations will be changing. The new Baseline Chute Concept of Operations will buy back approximately 700-800 $\mathrm{ft}$ in altitude. The LAV is able to take advantage of this extra altitude by shallowing out the trajectory and obtaining more downrange. With this change the percentage of failures is now less than $4 \%$, as compared to the $9.5 \%$ with the old Baseline Chute Concept of Operations (Figure 11 Top).

\section{Conclusions}

A successful abort is highly dependent on the requirements; a properly tailored Abort Motor thrust profile, and making use of the proper Concept of Operations. This paper serves to explain how all three components are dependent on each other. The requirements drive the solution to create a successful abort, whereas the Abort Motor thrust profile and the concept of operations determine how the requirements are achieved. Altering the LAS jettison time, which increases settling time after reorientation, has the largest overall impact on the concept of operations. The LAS jettison time change allows the controller to shallow out the trajectory, enabling a jettison of the LAS as close to apogee as possible, a necessity to meet the requirements of a one main parachute out case. In addition, altering the pitch maneuver shallows out the trajectory and pushes apogee closer to the new LAS jettison time. This paper has demonstrated the importance of settling time to a successful abort. In order to have reasonable attitudes and rates at drogue parachute deploy, and to avoid recontact with the LAS, it is vital to allow enough time to settle after reorientation to a heatshield forward attitude. However, too much settling time can decrease much needed altitude margin. The trade between settling time and performance is a fine line. For instance, by increasing settling time by 1.5 seconds, the total failures increase by $8 \%$. As mentioned, the current, pre-Preliminary Design Review, system does not close; therefore the solution given is the best current trade between all of the requirements. Future improvements that will be made during the Preliminary Design Review design cycle to the chute concept of operations and to the LAV should help tremendously in closing the system.

\section{References}

${ }^{1}$ Davidson, John B., "Orion Crew Exploration Vehicle Launch Abort System Guidance and Control Analysis Overivew," AIAA Conference Paper, to be published.

2 "Program to Optimize Simulated Trajectories II," https://post2.larc.nasa.gov.

${ }^{3}$ Justus, C. G. and Johnson, D. L., "The NASA/MSFC Global Reference Atmospheric Model: 1999 Version (GRAM-99)," NASA/TM-1999-209630, Marshall Space Flight Center, Alabama, May 1999.

${ }^{4}$ CAP Aerodynamics Team, "Orion Aerodynamic Databook, Ver 0.36 Draft 1,” Lyndon B. Jonson Space Center, Houston, Texas, Sept. 2007.

${ }^{5}$ Taylor, A., Machin, R., and Royall, P., "Developing the Parachute System for NASA's Orion - An Overview at Inception," AIAA Conference Paper No. 2007-2577, Williamsburg, VA, May 2007.

${ }^{6}$ Knacke, Theo, "Parachute Recovery Systems Design Manual," Para Publishing, Santa Barbara, CA, 1992.

${ }^{7}$ Personal communication, email. Nov. 2006. 